\title{
As relações entre deficiência visual congênita, condutas do espectro do autismo e estilo materno de interação'
}

\author{
Possible relations among congenital blindness, autistic \\ features and maternal interaction style
}

\author{
Ana Delias de SOUSA ${ }^{2}$ \\ Cleonice Alves BOSA ${ }^{3}$ \\ Cristina Neves HUGO $^{4}$
}

\begin{abstract}
Resumo
Este trabalho examina a possível ocorrência das condutas do espectro do autismo em crianças portadoras de deficiência visual congênita e focaliza os comprometimentos da habilidade de atenção compartilhada, da capacidade simbólica e de estereotipias motoras, além de investigar o estilo diretivo de interação das mães ao tentar engajar os seus filhos em brincadeiras. Participaram do estudo oito díades mãe-criança distribuídas em dois grupos: quatro com deficiência visual congênita e quatro com desenvolvimento típico. Realizou-se uma entrevista sociodemográfica e de desenvolvimento da criança com as mães e uma sessão de vídeo da interação mãe-criança em laboratório. Os resultados mostraram que duas das crianças com deficiência visual congênita apresentaram uma freqüência maior de comprometimentos de habilidade de atenção compartilhada comparadas às crianças com desenvolvimento típico, e duas crianças com deficiência visual congênita apresentaram estereotipias motoras, porém com baixa freqüência. Apenas uma das mães das crianças com deficiência visual congênita apresentou maior freqüência de diretividade materna comparada à mãe da criança com desenvolvimento típico, contrariando a expectativa inicial. Observou-se a ocorrência de brinquedo simbólico no grupo das crianças com deficiência visual congênita. Esses resultados contrariam algumas das expectativas da literatura. Conclui-se que as crianças com deficiência visual congênita não estão necessariamente em risco para desenvolver condutas do espectro do autismo.
\end{abstract}

Palavras-chave: autismo; brinquedo simbólico; estereotipias; relações mãe-criança.

\begin{abstract}
This study has examined the occurrence of autistic features in children with congenital blindness. Joint attention and symbolic play deficits, and stereotyped body movements were focused. Mother's interaction style was also investigated during playing episodes, while they were trying to engage their children. Eight child-mother dyads, 4 with congenital blindness and 4 sighted children were studied. A home-based interview about child's development and socio-demographic data has been performed, and a free-play session was conducted. Free-play sessions were used for coding both maternal and infant behaviors. The results, that are out of the literature expectations, have brought up

\section{$\boldsymbol{\nabla \nabla \nabla \nabla}$}

1 Artigo elaborado a partir da dissertação de A.D. SOUSA intitulada "As relações entre deficiencia visual congênita, condutas do espectro do autismo e estilo materno de interação". Universidade Federal do Rio Grande do Sul, 2003.

2 Instituto de Psicologia, Universidade Federal do Rio Grande do Sul. Porto Alegre, RS, Brasil.

3 Programa de Pós-Graduação em Psicologia, Universidade Federal do Rio Grande do Sul. Rua Ramiro Barcellos, 2600, Sala 110, 90035-003, Porto Alegre, RS. Correspondência para/Correspondence to: C.A. BOSA.E-mail:<cleobosa@uol.com.br>.

4 Mestranda em Psicologia, Programa de Pós-Graduação em Psicologia, Universidade Federal do Rio Grande do Sul. Porto Alegre, RS, Brasil. Agradecimentos: ao apoio do CNPq e às escolas que colaboraram com este estudo, em especial ao Instituto Santa Luzia.
\end{abstract}


only two blind children showed higher play deficits frequencies, and only one mother from the congenital blindness children group who had presented more maternal directive posture compared to the sighted children's mothers. It was also noted the presence of symbolic play in the congenital blindness group. These results suggest that children with congenital blindness may not be at risk, considering the autistic features development, as long as they are properly stimulated by their caregivers who are sensible to their cues and needs.

Key words: autism; symbolic play; stereotyped behavior; mother child relations.

A deficiência visual congênita (DVC) e sua relação com a interação social tem sido alvo de poucos estudos entre os pesquisadores do desenvolvimento infantil. Visto que o olhar exerce papel fundamental na interação (Klaus \& Klaus, 2001), é importante que se compreenda melhor como se desenvolvem os processos comunicativos entre cuidador e criança quando a visão não está presente. Inicialmente, entretanto, é preciso revisar o conceito de deficiência visual.

A compreensão desse conceito se vincula à própria definição do termo"deficiência". Segundo Amaral (1996), deficiência refere-se a uma perda ou anormalidade de estrutura ou função; incapacidade, à restrição de atividades em decorrência de uma deficiência; e desvantagem, à condição social de prejuízo resultante de deficiência e/ou incapacidade.

Deficiência visual, desse modo, é um termo que designa impedimentos de origem orgânica relacionados a doenças oculares, que podem levar a um mau funcionamento visual ou à ausência de visão (Batista \& Enumo, 2000). Para os autores, são raros os casos de cegueira total, em que uma pessoa não apresenta nenhum tipo de reação à luz.

Acerca da prevalência dessa condição, o número exato de pessoas com deficiência visual não é conhecido devido à falta de dados epidemiológicos. A Organização Mundial de Saúde (OMS) estimou que, na década de 1990, havia no mundo pelo menos 38 milhões de pessoas sob essa condição (World Health Organization, 1994), ou seja, $1 \%$ da população mundial apresentava algum grau dessa deficiência.

Atualmente, as distintas classificações de defiCiência visual se baseiam na avaliação da acuidade visual, \% campo visual, sensibilidade ao contraste, visão de cores e outros aspectos (Batista \& Enumo, 2000). A acuidade se refere à capacidade de discriminação de formas, avaliada através da apresentação de linhas, símbolos ou letras progressivamente menores. Quando a acuidade é baixa, a pessoa tem dificuldade para perceber formas, seja de perto, à distância, ou em ambas as situações.

As deficiências visuais podem ser congênitas ou adquiridas. Existe uma série de doenças na infância que podem produzi-las ou agravá-las, assim como acidentes em qualquer época da vida (Batista \& Enumo, 2000). É preciso que se considere a partir do nascimento a influência da ausência de visão no desenvolvimento, uma vez que a criança com DVC pode apresentar riscos para atrasos ou desvios em áreas importantes, tais como a comunicação e a cognição social, como acontece em outra patologias, como, por exemplo, no autismo (Recchia, 1997a).

Autismo tem sido definido como uma síndrome que envolve uma profunda distorção do processo do desenvolvimento infantil (Rutter, 1996). Desde 1980, diferentes sistemas diagnósticos (Rutter, 1978; World Health Organization, 1992; American Psychiatric Association, 2002) têm baseado seus critérios em problemas apresentados em três domínios (tríade de comprometimentos): a) danos qualitativos na interação social; b) danos qualitativos na comunicação verbal e não-verbal e no brinquedo imaginativo; e c) comportamento e interesses restritivos e repetitivos. O termo condutas do espectro do autismo tem sido empregado para qualquer comportamento presente nas três áreas de comprometimentos do DSM-IV-TR (American Psychiatric Association, 2002), independente do fato de os critérios para o diagnóstico de autismo serem ou não fechados.

Depreende-se que condições como autismo e deficiência visual congênita podem interferir na qualidade das interações iniciais da mãe com o bebêe, conseqüentemente, dificultar o desenvolvimento da atenção compartilhada. Tais interações vistas sob a perspectiva das teorias afetivas dependem das trocas de olhares entre mãe e bebê. Assim como os bebês parecem ter uma preferência por rostos humanos, os adultos talvez estejam programados para se encantarem com bebês recém-nascidos e serem atraídos por eles 
(Klaus, \& Klaus, 2001). Bowlby (1969), a partir de uma perspectiva etológica, destacou em seus estudos sobre o apego cuidador-criança que não só existe uma preferência precoce para olhar o rosto humano, como também para olhar o rosto da mãe, em vez de dirigir o olhar para outras pessoas. Quanto mais um bebê olha para a mãe, mais é provável que ela se mova em sua direção, faça gestos, fale ou cante para ele, acaricie-o ou o abrace, favorecendo, portanto, o desenvolvimento de habilidades comunicativas mais complexas. No final do primeiro ano de vida, um bebê possui um vocabulário restrito, mas procura trocar experiências com pessoas significativas e coopera, investigando e agindo sobre esse mundo compartilhado.

Atenção compartilhada pode ser definida como um conjunto de comportamentos comunicativos (verbais e não verbais) que objetivam iniciar e dividir com o cuidador as propriedades dos objetos e eventos ao redor (Mundy, Sigman \& Kasari, 1990). Nesse sentido, tanto no autismo como na DVC a limitação ou a ausência do olhar pode trazer dificuldades ao compartilhamento de experiências da díade mãe-bebê, durante a interação.

Ao se revisarem os estudos sobre a associação entre as condutas autistas e DVC, destacam-se importantes contribuições. Há evidências de similaridades entre crianças com DVC e autismo quanto a dificuldades na expressividade emocional e no reconhecimento da emoção (Rogers \& Puchalski, 1986; Minter, Hobson \& Pring, 1991). Também foi documentada a presença de estereotipias excessivas (Tröster \& Brambring, 1992). Para esses autores, uma explicação possível para esse fato seria a dificuldade da criança para atrair a atenção da mãe e exercer controle sobre o ambiente, o que produziria uma tendência ao isolamento social. De modo semelhante, Fernell, Jacobson e Gillberg (1998) ressaltaram a diferença entre sintomas referentes ao autismo e o que se denomina de blindisms (comportamentos "estranhos" exibidos pelas crianças com DVC). O padrão de tais comportamentos pode ser interpretado como adaptativo, diante da condição imposta pela deficiência.

No que se refere à interação social cuidadorcriança diante de condições atípicas do desenvolvimento, alguns achados devem ser destacados. De acordo com Kasari, Sigman, Mundy e Yirmina (1988) e
Trevarthen, Aitken, Papoudi e Robarts (1996), o estilo diretivo de interação identificado em mães de crianças com autismo teria como objetivo tentativas de eliciar a habilidade de atenção compartilhada. De fato, no estudo de Sigolo (2000), foi apontado que a presença de comportamentos diretivos em mães de crianças com atraso de desenvolvimento apresenta qualidades adaptativas. Isto quer dizer que, em decorrência das dificuldades que tais crianças apresentam, esses comportamentos podem ser considerados como não prejudiciais ao desenvolvimento, diferente de quando se pensa em crianças com desenvolvimento típico (DT).

Cabe ressaltar que na literatura encontram-se diferentes definições para o termo diretividade materna (Sigolo, 2000; Borges \& Salomão, 2003). Bosa (1998), por exemplo, considera comportamentos diretivos como gestos e/ou comportamento verbal que a mãe usa para dar instruções e estimular o filho ou, ao contrário, indicar discordância referente às ações do mesmo, tais como introdução insistente de brinquedos e reprovação dos atos seus. Mais especificamente, ao se tratar desse tópico no contexto da DVC, um dos raros estudos encontrados relatou que as informações descritivas que as mães das crianças com DVC fornecem, mesmo que sejam feitas de forma diretiva, são bastante importantes para a aquisição da linguagem dessas crianças (Pérez-Pereira \& Conti-Ramsden, 2001). De fato, os papéis da linguagem e do tato - como formas compensatórias possíveis que permitem o transcorrer da interação entre o cuidador e a criança com deficiência visual - vêm sendo apontados por diferentes autores (Urwin, 1984; Bigelow, 1986). Cabe salientar, ainda, que a aquisição da linguagem parece estar implicada no desenvolvimento do brinquedo.

Diferentes autores ressaltam que as crianças com desenvolvimento típico estão aptas a desenvolver a capacidade de brincar ao assistir e imitar as outras pessoas (Recchia, 1997b; Zanandrea, 1998; Silveira, Loguercio \& Sperb, 2000). Nesse sentido, a visão tem um papel de destaque, pois as crianças aprendem como se relacionar com o outro e com os objetos simplesmente porque podem ver o que está acontecendo.

No primeiro semestre de vida, o brinquedo é exploratório. A partir do segundo, a criança começa a verificar a funcionalidade dos objetos, como apertar botões e teclas. Mais tarde, aparece o brinquedo 
simbólico, de forma rudimentar, o qual progride da brincadeira dirigida ao self, até a de fingir atos. Ao final dos dois anos de idade, a criança passa a combinar brinquedos, durante a atividade de faz-de--conta. Entre dois e três anos o brinquedo adquire uma qualidade interacional importante ao caracterizar-se por cooperação e encenação de atos. Dos três aos quatro anos, a criança dirige-se a seus pares para juntas desempenharem papéis em um cenário imaginado. Nessa fase, as relações sociais vão se tornando mais flexíveis (Garvey, 1977; Howes, 1987).

A literatura mostra evidências controversas quanto à ocorrência de brinquedo simbólico ou de faz-de-conta no contexto da deficiência visual. Howlin, Baron-Cohen e Hadwin (1999) apresentam uma definição de brincadeira de faz-de-conta que tem sido empregada em estudos com autistas. Em um estudo de Tröster e Brambring (1994), de acordo com os relatos dos pais entrevistados, as crianças com desenvolvimento típico se engajavam em níveis mais complexos de brinquedo, sobretudo quando mais jovens. No que se refere às crianças com deficiência visual, essas interagiam menos freqüentemente com outras crianças comparadas às crianças do grupo-controle. Ainda, preferiam jogos e brinquedos sonoros e táteis, e raramente engajavam-se em brincadeira simbólica. Por outro lado, Ferguson e Buultjens (1995) observaram, mensalmente, um grupo de crianças com DVC em interação com seus pares em sessões de brinquedo livre, ao longo de um período de 18 meses, além de medirem o nível de desenvolvimento das crianças através de uma escala de desenvolvimento. Os resultados revelaram que as crianças que obtiveram escores mais altos na escala também exibiram um nível maior de brinquedo simbólico. As crianças com idade inferior a 18 meses, quando estimuladas por crianças mais velhas e com visão, apresentaram brincadeira simbólica e imitação.

As investigações nessa área apontam para dificuldades quanto ao brinquedo simbólico que in poderiam estar associadas a transtornos de linguagem (్) (Parsons, 1986; Rettig, 1994). Em um estudo recente

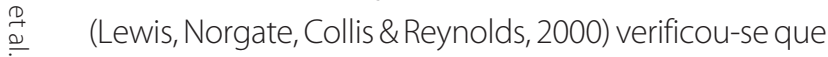
as crianças com DVC apresentaram freqüências mais baixas de brinquedo simbólico quando comparadas às crianças com desenvolvimento típico.
Estudos na área da interação social e DVC têm implicações para o desenvolvimento de estratégias alternativas de comunicação que auxiliem a interação entre as famílias e as crianças cujo desenvolvimento é atípico. Entretanto, a análise da questão da qualidade da interação entre os cuidadores e crianças com DVC revela a necessidade de mais investigações nessa área. O presente estudo tem como objetivo examinar possíveis condutas do espectro do autismo em crianças com DVC, comparadas às crianças com desenvolvimento típico. Ainda, investigar o estilo materno de interação e a qualidade do brinquedo nos dois grupos.

\section{Método}

Participam desse estudo oito díades mãecriança, sendo quatro díades com crianças com deficiência visual congênita (grupo 1) e quatro díades com desenvolvimento típico (grupo 2). As crianças foram emparelhadas pela idade, que variou entre dois e seis anos. As crianças apresentavam boas condições clínicas e moravam com a mãe biológica. As crianças do grupo 1 não portavam outras deficiências sensoriais e apresentavam acuidade visual semelhante, conforme registros médicos. As crianças do grupo 2 foram selecionadas em pré-escolas de ensino comum.

No que se refere ao nível de acuidade visual, em três casos ela não excedia a percepção de luz ou de sombra, no entanto, uma das crianças era totalmente cega, conforme dados obtidos nas entrevistas com as mães. De modo similar, essa população também demonstrou características heterogêneas quanto às etiologias (infecção por citamegalovírus; retinopatia de prematuridade; tumor de tipo retinoblastoma bilateral).

As mães tinham entre 24 e 36 anos. Os dois grupos também foram emparelhados de acordo com a escolaridade dos pais. As Tabelas 1 e 2 apresentam alguns dados sociodemográficos dos grupos, bem como os níveis de acuidade visual das crianças com deficiência visual.

\section{Instrumentos e materiais}

1. Consentimento livre e esclarecido: Esse formulário descreveu, de forma sucinta, os objetivos e os procedimentos da pesquisa e foi assinado pela mãe 
Tabela1. Características demográficas do grupo com deficiência visual congênita.

\begin{tabular}{|c|c|c|c|c|c|}
\hline Nome da criança* & Idade da criança & Acuidade visual & Idade da mãe & Escolaridade dos pais & Profissão \\
\hline Luís & 2 a 8 meses & $\begin{array}{l}\text { Mínima de luz vultos; } \\
\text { algumas cores }\end{array}$ & 30 & $\begin{array}{l}\text { Mãe: superior completo } \\
\text { Pai: superior incompleto }\end{array}$ & $\begin{array}{l}\text { Pedagoga } \\
\text { Supervisor/ empresa }\end{array}$ \\
\hline Daniel & 3 a 5 meses & Mínima de luz & 31 & $\begin{array}{l}\text { Mãe: médio completo } \\
\text { Pai: médio completo }\end{array}$ & $\begin{array}{l}\text { Funcionária pública } \\
\text { Sócio de empresa }\end{array}$ \\
\hline Laura & 5 anos & $\begin{array}{l}\text { Mínima de luz; } \\
\text { algumas cores }\end{array}$ & 24 & $\begin{array}{l}\text { Mãe: médio completo } \\
\text { Pai: fundamental completo }\end{array}$ & $\begin{array}{l}\text { Do lar } \\
\text { Dono de padaria }\end{array}$ \\
\hline Letícia & 5 a 7 meses & Perda total & 29 & $\begin{array}{l}\text { Mãe: médio completo } \\
\text { Pai: fundamental completo }\end{array}$ & $\begin{array}{l}\text { Do lar } \\
\text { Auxiliar de serviços gerais }\end{array}$ \\
\hline
\end{tabular}

* Nota: nomes fictícios.

Tabela 2. Características demográficas do grupo de crianças com desenvolvimento típico.

\begin{tabular}{|c|c|c|c|c|}
\hline Nome da criança* & Idade da criança & Idade da mãe & Escolaridade dos pais & Profissão \\
\hline Rodrigo & 2 a 7 meses & 34 & $\begin{array}{l}\text { Mãe: superior completo } \\
\text { Pai: superior completo }\end{array}$ & $\begin{array}{l}\text { Pedagoga } \\
\text { Advogado }\end{array}$ \\
\hline Mateus & 3 a 5 meses & 29 & $\begin{array}{l}\text { Mãe: médio completo } \\
\text { Pai: médio completo }\end{array}$ & $\begin{array}{l}\text { Do lar } \\
\text { Dono de loja }\end{array}$ \\
\hline Giana & 4 a 11 meses & 36 & $\begin{array}{l}\text { Mãe: superior completo } \\
\text { Pai: superior completo }\end{array}$ & $\begin{array}{l}\text { Bancária } \\
\text { Bancário }\end{array}$ \\
\hline Bruna & 5 a 6 meses & 29 & $\begin{array}{l}\text { Mãe: médio completo } \\
\text { Pai: médio completo }\end{array}$ & $\begin{array}{l}\text { Comerciátia } \\
\text { Funcionário público }\end{array}$ \\
\hline
\end{tabular}

* Nota: nomes fictícios.

da criança, em duas vias, permanecendo uma com a pesquisadora e a outra com a participante (CEP UFRGS, Protocolo n²003223).

2. Entrevista sobre dados sociodemográficos e de desenvolvimento: O roteiro de entrevista foi adaptado de Bosa (1998) e constitui-se de questões relacionadas a dados de identificação e de desenvolvimento das crianças, assim como informações sociodemográficas sobre sua família.

Questões específicas referentes à deficiência visual congênita foram incluídas (Exemplo: circunstâncias do diagnóstico, etiologia, tratamento). O formato do protocolo de registro também foi alterado, sendo que na versão utilizada no presente estudo a maioria das questões aparece na forma de perguntas (Sousa \& Bosa, 2002a).

3. Manual de observação e codificação dos episódios de atividades conjuntas mãe-criança: Uma sessão de 30 minutos de brinquedo livre foi utilizada para eliciar comportamentos sociocomunicativos infantis e maternos. Brinquedo livre foi definido como uma situação de brincadeira na qual nenhuma instrução específica é dada à mãe sobre como interagir com o filho. Essas sessões foram filmadas no laboratório de observação da Universidade Federal do Rio Grande do Sul (UFRGS). Os brinquedos foram escolhidos de acordo com a faixa etária dos participantes, utilizando-se brinquedos sonoros e de diferentes texturas.

Os vídeos produzidos foram utilizados para a codificação dos comportamentos da díade e o subseqüente processo de análise. Os comportamentos foram codificados com base num manual de observação desenvolvido por Bosa (1998) e adaptado para esse estudo (Sousa \& Bosa, 2002b).

4. Protocolo de registro de transcrição dos episódios de atividades conjuntas: Os episódios tinham seu início quando a criança se dirigia ao parceiro para a realização de uma atividade e terminavam quando o foco de interesse mudava para outro objeto ou evento, registrando-se o tempo de início e término de cada episódio em minutos e segundos. Após a identificação do episódio, realizou-se a transcrição detalhada dos comportamentos maternos e infantis durante os episódios (gestos, falas e ações das díades), desconsi- 
derando os cinco primeiros minutos filmados, por questões de ambientação da díade (Sousa \& Bosa, 2002c).

As categorias maternas foram redistribuídas em três: compartilhamento de tópico, diretividade e contato físico-afetivo, com base no protocolo originalmente desenvolvido por Bosa (1998). Buscou-se tal mudança pela necessidade de maior distinção e clareza quanto à definição de cada classe de comportamentos, para fins de codificação.

Os comportamentos infantis foram redistribuídos em atenção compartilhada, brinquedo e estereotipias. A categoria de atenção compartilhada teve sua definição operacional ampliada para facilitar a fidedignidade entre os codificadores. Os comportamentos não-verbais de atenção compartilhada passaram a ser comportamentos de orientação da cabeça/corpo e não mais direção do olhar, em função do grupo de crianças com deficiência visual congênita. Outras alterações nesse âmbito incluíram a ampliação quanto aos comportamentos gestuais da criança, tais como apontar, jogar, empurrar, entregar e mostrar objetos, no campo visual da mãe. Os comportamentos de requesta (pedido) presentes no manual para a codificação do estudo anterior foram excluídos, já que não constituíam o foco deste estudo. Finalmente, foi incluída a categoria estereotipias motoras. Dois bolsistas "cegos" aos objetivos do estudo foram treinados quanto à codificação dos comportamentos maternos e infantis, de forma independente. Esse treinamento ocorreu em duas etapas: discussão teórica e prática sobre a codificação de comportamentos, num total de 20 horas.

Esse protocolo foi modificado levando em conta a codificação por episódios de atividades conjuntas entre mãe e criança, ao invés da codificação por intervalos. Atividade conjunta foi definida como episódios interativos nos quais mãe e criança estavam envolvidas com o(s) mesmo(s) objeto(s) ou ação. Essa mudança refletiu a necessidade de se apreender a P fluência e a qualidade da interação da díade e não in comportamentos maternos e infantis isolados.

Para o processo de codificação foram criadas legendas (em cores e fontes diferentes) para cada subcategoria das categorias maternas e infantis. As subcategorias maternas foram registradas em letra maiúscula; as infantis em letra minúscula e em negrito.
As legendas eram localizadas ao lado de cada fala ou ação da díade, transcritas no protocolo.

Calculou-se o total de comportamentos maternos e infantis ao longo dos dez minutos codificados. O cálculo do total de cada categoria foi obtido somando suas subcategorias. Dessa forma, obtiveram-se índices de freqüência para as categorias maternas (compartilhamento de tópico, diretividade e contato físico afetivo) e para as categorias infantis (condutas autistas, atenção compartilhada, estereotipias; brinquedo - exploratório, funcional e simbólico). O cálculo do índice de concordância entre os codificadores foi realizado com base em Bakeman e Gottman (1999).

5. Registro de Qualidade do Brinquedo: Com base nas definições de brinquedo exploratório, funcional e simbólico, contidas no manual de observação e codificação (Sousa \& Bosa, 2002b), verificaram-se a qualidade bem como as porcentagens desses três níveis de brinquedo nos dois grupos. O registro foi realizado no mesmo protocolo de transcrição de atividades conjuntas entre mãe e criança anteriormente citado.

Quanto aos procedimentos, o recrutamento das crianças com DVC foi feito em clínicas e escolas especializadas nessa condição. Para tanto, a pesquisadora reuniu-se com os psicólogos dos locais para apresentação e esclarecimentos sobre o estudo.

Posteriormente, a pesquisadora entrou em contato com os responsáveis pela criança, por telefone, explicando sucintamente os objetivos do estudo, formalizando o convite para participarem da pesquisa e agendando um horário para a realização da entrevista.

As entrevistas e o preenchimento do Consentimento Livre e Esclarecido foram realizados, para os dois grupos, no domicílio de cada dupla. Nessa oportunidade, foram agendadas as filmagens realizadas em um laboratório de observação do Instituto de Psicologia.

\section{Resultados}

O número de episódios variou similarmente nos dois grupos, considerando que duas das díades mãe-criança com DVC tiveram mais episódios de atividade conjunta comparadas aos seus controles. As díades do outro grupo (com DT), do mesmo modo, apresentaram mais episódios de atividade conjunta ao serem comparadas com as díades com crianças com DVC. 
Foram calculadas médias e desvios-padrão do total de episódios e da duração, em segundos. Encontrou-se, para o grupo com DVC, média de 11,00 $(\mathrm{dp}=1,63)$ episódios, tendo em média 51,5 $(\mathrm{dp}=17,00)$ segundos; e para o grupo com DT, $m=11,75(\mathrm{dp}=0,50)$ episódios, sendo a média de duração igual $56(\mathrm{dp}=9,56)$ segundos. Constatou-se que apenas uma das díades do grupo das crianças com DVC apresentou maior duração média de episódios de atividade conjunta.

No que se refere aos comportamentos maternos, foram calculadas as porcentagens das três categorias de comportamentos: compartilhamento de tópico (CT), diretividade materna (DM) e contato físico afetivo (CFA). Tais porcentagens foram calculadas pela soma de cada uma de suas modalidades, verbais e não verbais, dividida pelo total de comportamentos maternos.

A maioria das mães do grupo das crianças com DVC apresentou maiores porcentagens de compartilhamento de tópico, comparadas às mães das crianças com DT (Tabela 3). No que se refere à categoria de contato físico afetivo, apenas uma mãe apresentou porcentagem inferior a 1\%. Destacam-se os dados referentes à diretividade materna. Ao contrário das expectativas iniciais do estudo, somente uma das mães do grupo das crianças com DVC foi mais diretiva comparada à mãe do grupo com DT.

Quanto aos comportamentos infantis, foram calculadas as freqüências simples das duas categorias de comportamento: atenção compartilhada (AC) e estereotipias motoras (EM). O cálculo para a obtenção dessas freqüências foi realizado com base na soma de cada uma de suas modalidades, verbais e não verbais, dividida pelo total das mesmas (Tabela 4).

De modo similar pode ser verificado que as freqüências simples de atenção compartilhada variaram nos dois grupos. Contrariando as expectativas iniciais, duas crianças com DVC (1 e 4) apresentaram freqüências maiores dessa categoria comparadas aos seus controles. No outro grupo (com DT), do mesmo modo, duas crianças (2 e 3) apresentaram freqüências maiores comparadas às crianças com DVC.

No que se refere às estereotipias motoras, conforme o esperado, as crianças do grupo com DT não apresentaram esse tipo de comportamento. Por outro lado, duas crianças com DVC apresentaram estereotipias, embora com freqüências baixas.
Quanto ao tipo de brinquedo, obteve-se sua freqüência total nos dois grupos pela soma das freqüências das seguintes classificações: exploratório (E), funcional (F) e simbólico (S). Todas as crianças do grupo com DVC apresentaram porcentagens maiores de brinquedo exploratório, comparadas às crianças do grupo com DT. Similarmente, no que diz respeito ao brinquedo funcional, as porcentagens foram superiores no grupo das crianças com DVC (em três dos quatro casos). É interessante notar que a maioria das crianças com DVC apresentou brinquedo simbólico, ainda que em porcentagens inferiores às crianças do grupo com DT (Tabela 5).

Tabela 3. Porcentagens dos comportamentos maternos nos grupos com DVC e com DT.

\begin{tabular}{lcccccccc}
\hline \multirow{2}{*}{ Mães } & \multicolumn{3}{c}{ DVC (\%) } & & \multicolumn{3}{c}{ DT (\%) } \\
\cline { 2 - 3 } \cline { 6 - 8 } & CT & DM & CFA & & CT & DM & CFA \\
\hline 1 & 82 & 18 & - & & 80 & 20 & - \\
2 & 69 & 31 & - & & 80 & 20 & 0,5 \\
3 & 92 & 8 & - & & 84 & 16 & - \\
4 & 81 & 19 & - & & 69 & 31 & - \\
\hline
\end{tabular}

DVC= Deficiência Visual Congênita; DT= Desenvolvimento Típico; $C T=C o m$ partilhamento de Tópico; DM= Diretividade Materna; CFA= Contato Físico Afetivo.

Tabela 4. Freqüências simples dos comportamentos infantis nos grupos com DVC e com DT.

\begin{tabular}{lcccccc}
\hline \multirow{2}{*}{ Crianças } & \multicolumn{3}{c}{ DVC } & \multicolumn{3}{c}{ DT } \\
\cline { 2 - 3 } \cline { 5 - 6 } \cline { 5 - 6 } & AC $(f)$ & EM $(f)$ & & AC $(f)$ & EM $(f)$ \\
\hline 1 & 134 & 6 & & 129 & - \\
2 & 72 & 1 & & 139 & - \\
3 & 51 & - & & 139 & - \\
4 & 135 & - & & 129 & - \\
\hline
\end{tabular}

DVC=Deficiência Visual Congênita; DT= Desenvolvimento Típico; $A C=$ Atenção Compartilhada; $\mathrm{EM}=$ Estereotipias Motoras.

Tabela 5. Porcentagens dos tipos de brinquedos nos grupos com DVC e com DT.

\begin{tabular}{lcccccccc}
\hline \multirow{2}{*}{ Crianças } & \multicolumn{3}{c}{ DVC (\%) } & & \multicolumn{3}{c}{ DT (\%) } \\
\cline { 2 - 3 } \cline { 7 - 8 } & $E$ & $F$ & $S$ & & $E$ & $F$ & $S$ \\
\hline 1 & 34 & 12 & 53 & & 5 & 5 & 53 \\
2 & 36 & 21 & 36 & & 25 & 14 & 52 \\
3 & 61 & 29 & 10 & & 4 & 2 & 94 \\
4 & 28 & 3 & 68 & & 17 & 3 & 80 \\
\hline
\end{tabular}

DVC= Deficiência Visual Congênita; DT= Desenvolvimento Típico; E= Exploratório; F= Funcional; S= Simbólico. 


\section{Discussão}

O estudo teve como objetivo central a investigação da presença de possíveis condutas do espectro do autismo em crianças portadoras de deficiência visual congênita (DVC). Examinaram-se, entre outros aspectos, a habilidade de Atenção Compartilhada (AC), as estereotipias motoras e a qualidade do brinquedo.

Nesse sentido, os resultados foram parcialmente contrários ao esperado, pois das quatro crianças com DVC, duas apresentaram freqüências maiores de AC comparadas às crianças com DT. Cabe salientar que, durante a exploração dos objetos, as crianças utilizaram tanto modalidades verbais (comentários, verbalizações e perguntas) como não verbais de AC (orientação da cabeça/corpo em direção ao campo visual da mãe; entregar e/ou colocar objeto no campo visual da mãe). O reconhecimento dos brinquedos nesse grupo de crianças era feito pelo tato e também através da fala. Uma das crianças, por exemplo, mantinha a mãe informada a respeito de suas metas e desejos durante os episódios de atividade conjunta, narrando cada uma de suas ações e idéias. Pensa-se que tais crianças, em virtude de sua privação sensorial, necessitem de mais tempo para apreender a natureza dos objetos que estão explorando, para, posteriormente, brincar simbolicamente com eles.

Pensa-se que as mães dessas crianças tiveram um papel decisivo para que elas pudessem exibir maiores freqüências de AC comparadas aos controles. Essas mães foram justamente as que se mostraram mais sensíveis em relação às necessidades das crianças ao descreverem as propriedades dos brinquedos, além de buscarem semelhanças com os brinquedos que seus filhos possuíam em casa. Com isso, as crianças mantinham-se interessadas nas brincadeiras. Para Bowlby (1969), a habilidade do cuidador para entender os sinais da criança e responder adequadamente a eles $\rightarrow \quad$ éa base do apego mãe-bebê.

ô No que se refere às estereotipias motoras, duas \ das crianças com DVC apresentaram esse compor$\stackrel{D}{\stackrel{D}{D}}$ tamento, conforme o esperado. Salienta-se que essas ocorreram em momentos nos quais as crianças demonstravam excitação ou frustração durante as brincadeiras. Segundo a literatura revisada, as estereotipias em portadores de DVC podem ser geradas devido à insegurança em relação ao ambiente, ou à privação sensorial. Chama-se a atenção para o fato de que as sessões de brinquedo livre foram filmadas no laboratório de observação da UFRGS, local provavelmente mais estranho para elas do que para as crianças com DT.

Quanto ao estilo materno de interação, apenas uma das mães do grupo das crianças com DVC apresentou maior freqüência de diretividade materna. Observou-se que quanto maior a diretividade, menor o compartilhamento de interesse pelo brinquedo com a mãe, apresentando, portanto, freqüência menor de AC. Por outro lado, a mãe da criança que apresentou a menor freqüência de AC do estudo foi extremamente ausente durante a interação, ainda que tenha demonstrado compartilhamento de tópico, o que foi feito silenciosamente. Essa mãe demonstrou estar pouco sintonizada com as pistas não-visuais dadas pela filha.

Os resultados referentes ao brinquedo corroboraram em parte a expectativa inicial do estudo. As crianças com DVC apresentaram brinquedo simbólico. Depreende-se a partir das evidências encontradas no estudo e dados apontados pela literatura que a necessidade de as crianças com DVC apreenderem um ambiente primordialmente visual parece ter sido facilitada pela habilidade materna em descrever as propriedades dos objetos e ajudar a criança a usar e descobrir caminhos alternativos durante a exploração (Exemplo: tato).

\section{Conclusão}

Conclui-se que as crianças com DVC investigadas não parecem estar em risco para o desenvolvimento de condutas do espectro do autismo, uma vez que foram estimuladas apropriadamente pelas mães, que se mostraram sensíveis às suas pistas e necessidades. Sugere-se que estudos futuros a respeito dessa temática tenham investigações de caráter longitudinal para que mudanças ao longo do tempo possam ser avaliadas, bem como para que o impacto da DVC possa ser observado em diferentes estágios do desenvolvimento. Ademais, faz-se necessário que se invista na criação e adaptação de instrumentos de avaliação do 
desenvolvimento, já que a carência desses é uma característica comum a inúmeros estudos que pesquisam a deficiência visual. Nesse sentido, pensa-se ser importante dar atenção às rotas e aos estilos alternativos buscados pelas crianças com DVC para se desenvolverem. Conseqüentemente, programas educacionais e de intervenção podem ser beneficiados a partir dos entendimentos de como essas crianças aprendem sobre si mesmas e se relacionam com o mundo (cuidadores, educadores, pares etc).

Em última instância, parece ser adequado o ponto de vista de alguns autores de pensarem a deficiência visual como uma perda ou anormalidade de estrutura ou função que pode levar a um mau funcionamento visual ou à ausência de visão (Amaral, 1996; Masini, 1999; Batista \& Enumo, 2000). Dessa forma, examina-se com cuidado os possíveis déficits acarretados por tal condição, já que eles podem ser compreendidos como formas diferentes de se relacionar com o mundo, e não tanto como riscos ou, de fato, atrasos do desenvolvimento.

\section{Referências}

Amaral, L.A. (1996). Deficiência: questões conceituais e alguns de seus desdobramentos. Cadernos de Psicologia, $1(1), 3-12$

American Psychiatric Association. (2002). Manual de diagnóstico e estatístico de transtornos mentais: texto revisado. Porto Alegre: Artes Médicas.

Bakeman, R., \& Gottman, J.M. (1999). Observing interaction. Cambridge: University Press.

Batista, C.G., \& Enumo, S.R.F. (2000). Desenvolvimento humano e impedimentos de origem orgânica: O caso da deficiência visual. In H.A. Novo \& M.C.S. Meneandro (Orgs.). Olhares diversos: estudando o desenvolvimento humano (pp.157-174). Vitória: Programa de Pós-Graduação em Psicologia UFES.

Bigelow, A.E. (1986). The development of reaching in blind children. British Journal of Developmental Psychology, 4, 355-366.

Borges, L.C., \& Salomão, N.M.R. (2003). Aquisição da linguagem: Considerações da perspectiva da interação social. Psicologia: Reflexão e Crítica, 16 (2), 327-336.

Bosa, C. (1998). Affect, social comunication and self-stimulation in children with and without autism: a systematic observation study of requesting behaviours and joint attention. Unpublished doctoral dissertation, Institute of Psychiatric, University of London.

Bowlby, J. (1969). Attachment and loss. London: Hogarth Press.
Comitê Nacional de Ética em Pesquisa. (1996). Consentimento livre e esclarecido. Brasília: Ministério da Saúde.

Ferguson, R., \& Buultjens, M. (1995). The play behaviour of young blind children and its relationship to developmental stages. British Journal of Visual Impairment, 13 (3), 100-107.

Fernell, E., Jacobson, L., \& Gillberg, C. (1998). Relation between blindness due to retinopathy of prematurity and autistic spectrum disorders: a population-based study. Developmental Medicine \& Child Neurology, 40 (5), 297-301.

Garvey, C. (1977). Play. Cambridge, MA: Harward University Press.

Howes, C. (1987). Peer interaction of young children. Monographs of the Society for Research in Child Development, 53, series 217

Howlin, P., Baron-Cohen, S., \& Hadwin, J. (1999). Teaching children with autism to mind read: a practical guide for researchers and parents. Chichester: John Wiley \& Sons.

Kasari, C., Sigman, M., Mundy, P., \& Yirmina, N. (1988). Caregiver interactions with autistic children. Journal of Abnormal Child Psychology, 16 (1), 45-56.

Klaus, M.H., \& Klaus, P.H. (2001). Seu surpreendente recém-nascido. Porto Alegre: ArtMed.

Lewis, V., Norgate, S., Collis, G., \& Reynolds, R. (2000). The consequences of visual impairment for children's symbolic and functional play. British Journal of Development Psychology, 18, 449-464.

Masini, E.F.S. (1999). A pessoa com baixa visão: Desenvolvimento de sua eficiência visual. Temas sobre Desenvolvimento, 8 (46), 28-34.

Minter, M., Hobson, R.P., \& Pring, L. (1991). Recognition of vocally expressed emotion by congenitally blind children. Journal of Visual Impairment \& Blindness, 85, 411-415.

Mundy, P., Sigman, M., \& Kasari, C. (1990). A longitudinal study of joint attention and language development in autistic children. Journal of Autism and Developmental Disorders, 20 (1), 115-28.

Parsons, S. (1986). Function of play in low vision children (part 2): Emerging patterns of behaviour. Journal of Visual Impairment \& Blindness, 80, 777-784.

Pérez-Pereira, M., \& Conti-Ramsden, G. (2001). The use of directives in verbal interactions between blind children and their mothers. Journal of Visual Impairment \& Blindness, 95, 133-149.

Recchia, S.L. (1997a). Establishing intersubjective experience: Developmental chalenges for young children with congenital blindness and autism and their caregivers. In V. Lewis \& G.M. Collis (Orgs.). Blindness and psychological development in young children (pp. 116-129). Leicester, UK: British Psychological Society Books.

Recchia, S.L. (1997b). Play and concept development in infants with severe visual impairments: a constructivist view. Journal of Visual Impairment \& Blindness, 91, 401-406.

Rettig, M. (1994). The play of young children with visual impairments: Characteristics and interventions. Journal of Visual Impairment and Blindness, 88, 410-420. 
Rogers, S.J., \& Puchalsky, C.B. (1986). Social smiles of visually impaired infants. Journal of Visual Impairment \& Blindness, 80, 863-865

Rutter, M. (1978). Language disorder and infantile autism. In M. Rutter \& E. Schopler (Orgs.). Autism: a reappraisal and acquired cognitive disorders (pp. 247-264). New York: Raven Press.

Rutter, M. (1996). Autism research: Prospectus and priorities. Journal of Autism and Developmental Disorders, 26 (2), 257-275.

Sigolo, S.R. (2000). Diretividade materna e socialização de crianças com atraso de desenvolvimento. Cadernos de Psicologia e Educação PAIDÉIA- RP, 10 (19), 47-54.

Silveira, A., Loguercio, L., \& Sperb, T. (2000). A brincadeira simbólica de crianças deficientes visuais pré-escolares. Revista Brasileira de Educação Especial, 6 (1), 133-146.

Sousa, A.D., \& Bosa, C. (2002a). Entrevista sobre Dados Sociodemográficos e de Desenvolvimento. Instituto de Psicologia UFRGS, Porto Alegre. (Instrumento de pesquisa não-publicado)

Sousa, A.D., \& Bosa, C. (2002b). manual de observação e codificação dos episódios de atividades conjuntas mãe-criança. Instituto de Psicologia UFRGS, Porto Alegre. (Instrumento de pesquisa não-publicado)

Sousa, A.D., \& Bosa, C. (2002c). Protocolo de Registro de Transcrição dos Episódios de Atividades Conjuntas. Instituto de Psicologia - UFRGS, Porto Alegre. (Instrumento de pesquisa não-publicado)
Trevarthen, C., Aitken, K., Papoudi, D., \& Robarts, J. (1996). Children with autism diagnosis and intervention to meet their needs. London: Jessica Kingsley.

Tröster, H., \& Brambring, M. (1992). Early social-emotional development in blind infants. Child Care Health and Development, 18 (4), 207-227.

Tröster, H., \& Brambring, M. (1994). The play behaviour and play materials of blind and sighted infants and preschoolers. Journal of Visual Impairment \& Blindness, 88, 421-432.

Urwin, C. (1984). Language for absent things: Learning from visually handicapped children. Topics in Language Disorders, 4 (4), 24-37.

World Health Organization. (1992). The ICD-10 Classification of Mental and Behavioural Disorders: Clinical descriptions and diagnostic guidelines. Geneva: World Health Organization.

World Health Organization. (1994). World Prevalence of Blindness Programme for the prevention of Blindness and Deafness (PBD). Geneva: World Health Organization.

Zanandrea, M. (1998). Play, social interaction, and motor development: practical activities for preschoolers with visual impairments. Journal of Visual Impairment \& Blindness, 92, 176-188.

Recebido para publicação em 24 de novembro de 2004 e aceito em 20 de julho de 2005. 